\title{
Conexões na paisagem - A arborização urbana como infra-estrutura bioconectora
}

\section{Connections in the landscape - Urban street trees as a bioconnector infrastructure}

Grupo de Estudos e Práticas Camboatã Território - Natureza*, Ana Maria Antunes Coelho**,

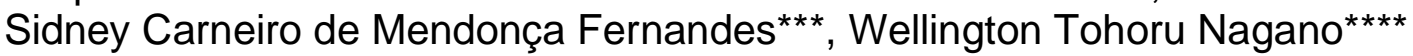

*Grupo que reúne pesquisadores cujo objetivo é contribuir para que a pesquisa científica extra-pole os âmbitos acadêmicos, promovendo reflexões e ações concretas no território. Seus principais temas são: natureza e cidade; ecologia urbana; espaços públicos e serviços ecos-sistêmicos

**Companhia de Desenvolvimento Habitacional e Urbano do Estado de São Paulo, Brasil, acoelho@cdhu.sp.gov.br

***Programa de Pós-Graduação em Arquitetura e Urbanismo da Universidade São Judas Tadeu, Brasil, sidcm.fernandes@gmail.com

${ }^{* \star \star \star}$ Secretaria do Verde e Meio Ambiente de São Paulo, Brasil, wtnagano@prefeitura.sp.gov.br

\section{Palavras-chave:}

Ecossistemas urbanos;

Paisagem urbana;

Vegetação urbana.

\section{Keywords:}

Urban ecosystems;

Urban landscape;

Urban vegetation

\section{Resumo}

Apresentamos o grande espaço público urbano, representado pelas ruas da cidade, como potencial para dar suporte a uma infraestrutura de vegetação, que permite a continuidade e conexão dos maciços verdes existentes, com capacidade para amenizar o clima, reduzir a poluição ambiental, melhorar a qualidade do ar e trazer a riqueza da diversidade da fauna e flora para junto dos usuários da cidade, de forma a enriquecer o cotidiano urbano. As vantagens se encontram em aproveitar uma estrutura urbana existente de modo a incrementar as iniciativas referentes à arborização urbana dos vários agentes, pensar global para implantar local, incentivar o conhecimento das relações ecossistêmicas nas áreas urbanas e proporcionar qualidade ambiental para a cidade como um todo.

\section{Abstract}

We present the street as the large public space in the cities, as a potentia to support the infrastructure of vegetation, with allows the continuity and connections between existing green areas, with the capacity to alleviate the climate, reduce the air pollution, improve the air quality and bring the rich diversity of fauna and flora to the inhabitants of the city, in order to enrich the urban daily life. The advantages are found in taking an existing urban structure to increase the initiatives related to street tree planting by various stakeholders, think globally to implement local, encourage knowledge about ecosystems relations in urban areas and provide environmental quality for the city as a whole.

aro.uro

úmero 32 | set - dez de 202 Recebido: 30/07/2021 DOI: $10.37916 /$ arq.urb.vi32.534

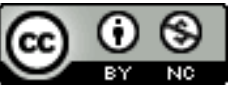




\section{Introdução}

A cidade é um de nossos principais artefatos, construída com os elementos presentes na natureza, que resulta em nosso lugar de habitar, nossa casa, parte de nossa inserção como transformadores, assim como tantos outros agentes em diferentes escalas e intensidades, redefinindo essa natureza em que estamos inseridos. No entanto, em nosso imaginário, estar em contato com a natureza significa sairmos desse ambiente transformado por nós, para nos refugiarmos em locais onde esse atuar humano esteja camuflado ou de alguma forma se apresente como uma natureza intocada. Essa busca pela antítese daquilo que construímos é um paradoxo, já que temos tecnologia e conhecimento para produzirmos uma cidade mais alinhada com o que entendemos ser qualidade do ambiente, mas não é isso o que praticamos.

Sabemos que a vegetação é um dos elementos que mais caracteriza essa qualidade, uma vez que tem papel importante na dinâmica dos outros elementos que compõem esse ambiente, seja melhorando a qualidade e permeabilidade do solo, filtragem, umidade e qualidade do ar, tem importância fundamental em todo o ciclo e dinâmica da água, além de conexões bióticas com várias espécies.

No entanto, retomando a ideia do conhecimento parcelado e/ou especializado, a vegetação em geral está relacionada à presença de reservas verdes, parques e praças, sendo muitas vezes desconsiderado o papel que representa o seu plantio pontual e extensivo, que no somatório, pode trazer grande incremento de qualidade em áreas absolutamente carentes desse elemento.

Nesse sentido, ao abordarmos a rua como o espaço público que permeia e une toda a cidade e se caracteriza como o suporte básico da infraestrutura urbana, além da multiplicidade de usos e papéis que desempenha, propomos discutir a vegetação como mais um tipo de infraestrutura, fundamental para pensarmos em uma cidade que se alinha aos serviços ecossistêmicos, fazendo com que essa articulação em rede possa ser suporte para as várias relações bióticas se multiplicarem e percorrerem todo o espaço urbano, como um grande sistema, situação que pressupõe a interdisciplinaridade e interdependência de saberes. Importante destacar que as ruas e suas calçadas compreendem o maior espaço público da cidade e têm potencial para nos apropriarmos também do ponto de vista ambiental.
Essa abordagem é possível quando adotamos a transversalidade das diversas ciências, como arquitetura, engenharia, urbanismo, biologia, educação e gestão pública. É necessária a interdisciplinaridade e uma visão contextualizada da arborização urbana, mesmo que as ações sejam locais, porém articuladas no global.

\section{Arborização Urbana em São Paulo}

Por meio de normas, legislações e políticas públicas, o Poder Público é tanto promotor quanto indutor da arborização urbana, como forma de ampliação das áreas verdes dos bairros, componente do microclima, integrante do ecossistema local (Fig. 3) e tornando os percursos mais agradáveis para os moradores.

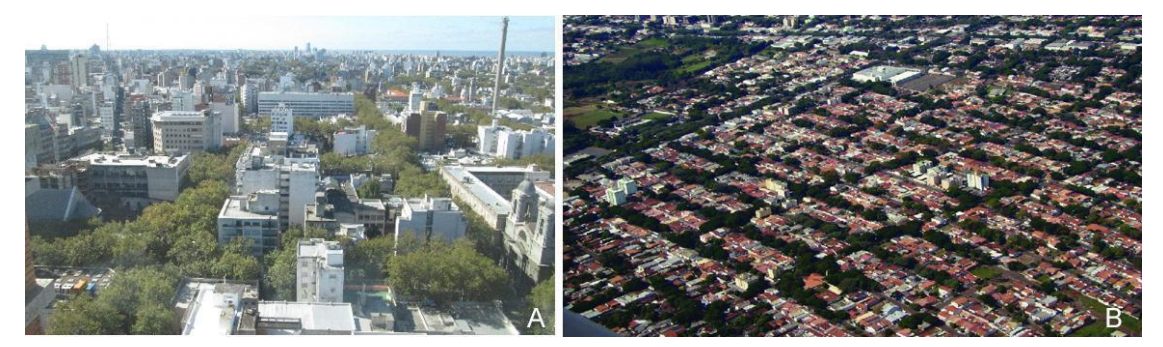

Figura 3 - Arborização urbana em Montevidéu (A), Uruguai, e em Maringá (B). Fontes: Wellington Tohoru Nagano e Maria Helena Preto, respectivamente.

Discutir arborização urbana no Brasil é refletir como são as calçadas de nossas cidades (Fig. 4), com problemas de largura, interferências com a infraestrutura subterrânea e aérea, desníveis, relação entre imóveis lindeiros, entre outros, de tal forma que não favorecem o pedestre, e tornam-se impeditivos para aqueles com restrições de locomoção, sejam idosos, pessoas com deficiência ou aqueles que estão com carrinho de bebê ou compras, por exemplo. Apesar de domínio público, o projeto e a manutenção da calçada são de responsabilidade do proprietário do imóvel, resultando em diversos tipos de desenhos. 


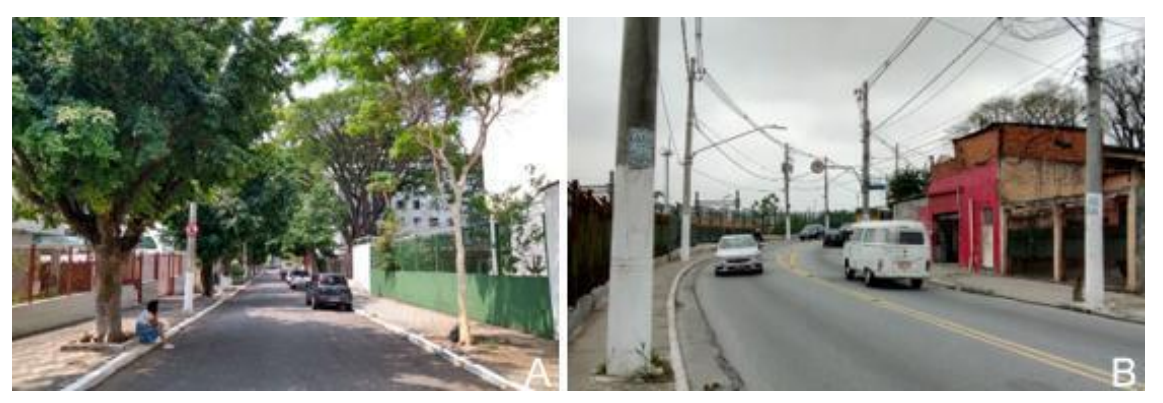

Figura 4 - Rua Jerônimo da Mendonça (A), na Mooca, com calçada larga, arborizada e a sombra da árvore é aproveitada para o descanso de uma pessoa. Em Guaianazes, a Avenida Salvador Gianetti (B) possui calçadas estreitas e postes que impedem a circulação de pedestres. Fontes: Wellington Nagano.

No município de São Paulo, por exemplo, a arborização urbana sempre era tratada de forma parcelada e foi no Plano Diretor Estratégico (PDE) de 2002 que aparece de forma mais estruturada, por meio de plantio no sistema viário, em avenidas de fundo de vale e de programas de arborização nas escolas (SÃO PAULO, 2002).

Um passo importante para o inventário da arborização urbana foi o cadastramento da vegetação arbórea realizado em 1985, ainda de forma manual, por meio de aerofotogrametria, com visitas e levantamentos in loco (SÃO PAULO, 1988), que se tornou um importante elemento de preservação da vegetação existente na cidade, por meio do Decreto 30.443/1989. No entanto, faltava um sistema de gestão para o acompanhamento desse patrimônio ao longo do tempo. Mais recentemente, com o desenvolvimento tecnológico, o Sistema de Gerenciamento de Arborização Urbana (SISGAU), elaborado para a Secretaria do Verde e Meio Ambiente (SVMA) pelo Instituto de Pesquisas Tecnológicas (IPT), apresenta dados de espécie, local, estado fitossanitário, altura, entre outras, das árvores existentes.

Entre 2009 e 2012, a cidade de São Paulo plantou mais de 800 mil árvores em vias, áreas públicas e nos 50 parques municipais implantados no período. A SVMA, por meio da Diretoria de Gestão Descentralizada (DGD), fazia programas de arborização urbana junto às áreas públicas, sistema viário e escolas municipais.

Desde então, surgiram normas, legislações e manuais relativos à arborização urbana: Portaria SVMA 61/2011, com relação das espécies nativas da Mata Atlântica a serem utilizadas nos processos de compensação ambiental; o Manual Técnico de
Arborização Urbana (2015), com ênfase no plantio nas calçadas, e o Artigo 286 do Plano Diretor Estratégico de 2014, que estabeleceu as diretrizes para o Plano Municipal de Arborização Urbana (PMAU). Segundo o artigo, o PMAU deveria conter os inventários arbóreos, diagnóstico de déficit de vegetação por região, identificação de áreas para plantio, as espécies indicadas, gestão da arborização e programas de educação ambiental (SÃO PAULO, 2014).

As ações de arborização urbana em São Paulo não ficam restritas apenas à municipalidade. O Governo Estadual, por meio da Secretaria de Infraestrutura e Meio Ambiente (SIMA), tem legislação importante referente à vegetação e recomposição de áreas em novos empreendimentos, em especial para vegetação nativa e áreas de preservação ao longo de córregos e nascentes, por exemplo, e tem conseguido resultados significativos em locais ambientalmente degradados, como a recuperação da área do Parque Villa Lobos, o plantio às margens do Rio Pinheiros e a exigência de Projeto de Recuperação Ambiental, contendo paisagismo e arborização, dentro dos Programas de Recuperação de Interesse Social (PRIS) nas Área de Proteção e Recuperação de Mananciais ocupadas por loteamentos irregulares e desprovidos de infraestrutura.

Também surgem propostas que utilizam a arborização urbana como parte do redesenho das ruas. Em 2015, um projeto-piloto da Prefeitura de São Paulo plantou ipêsamarelos no eixo da Avenida Patrocínio Paulista (Figs. 5A e 5B) e na Praça Adelina Tobias de Aguiar (Fig. 5C).

Apesar de benefícios como redução de velocidade dos veículos e melhor segurança para o pedestre, o projeto-piloto não seguiu adiante devido à repercussão negativa de outros locais, que temiam que ocorresse o mesmo em suas ruas (PAIVA, 2018).

Atualmente, as árvores cresceram e a praça ganhou mais área permeável, porém seu projeto não incorporou a criação de infraestrutura verde no local, sem drenar as águas pluviais do entorno (Fig. 5D). Perdeu a chance de incorporar a infraestrutura verde à arborização urbana, de modo a atenuar as mudanças climáticas. Por outro lado, o projeto-piloto mostrou as possibilidades de arborização urbana em locais alternativos, como esquinas, entre vagas de veículos, rotatórias e espaços livres. 


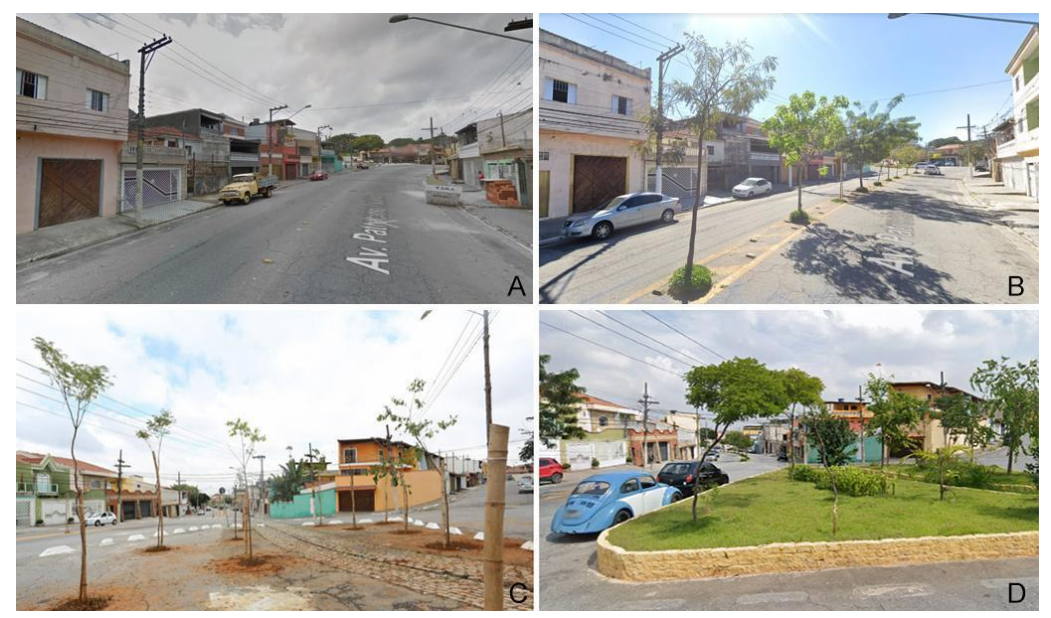

Figura 5 - Avenida Patrocínio Paulista em 2015 (A) e 2020 (B). Praça Adelina Tobias com as árvores plantadas na mesma época (C). Em 2019, o asfalto é substituído por vegetação, mas a mureta-guia impede absorção das águas pluviais das vias do entorno (D). Fotos: Fábio Arantes / SECOM (C) e Google Street View.

Fazer planos de arborização urbana em uma cidade consolidada e heterogênea como São Paulo exige respostas adaptadas às condições locais e, muitas vezes, dependem de ações integradas para a viabilização de espaços em áreas com infraestrutura mais restrita. Os coletivos urbanos têm surgido na cidade e são agentes que atuam na escala local. A associação deles com os órgãos públicos pode intensificar a arborização urbana e difundir sua importância, devido à maior inserção no território que o Poder Público, capacidade de articulação com a população e de engajamento, com mão-de-obra e voluntários para a gestão. Ao Poder Público caberia o apoio institucional, o corpo técnico, o planejamento e o fornecimento de insumos.

A associação com coletivos urbanos não exime o Poder Público de ser protagonista na arborização urbana, mas aceita novas formas de políticas públicas. Ainda são necessárias articulações intersecretariais, estímulos mais concretos para o plantio em calçadas e melhor comunicação do benefício da arborização urbana o local.

\section{Gestão urbana da arborização}

A arborização urbana também passa pela gestão das árvores durante seu ciclo de vida, com crescimento, amadurecimento e envelhecimento. Além do risco de surgirem doenças, tornando-as frágeis durante eventos climáticos, elas podem ser alvo de vandalismo ou acidentes. É necessário o monitoramento constante das árvores em relação às doenças e ações externas, com remoção e substituição por espécies novas e mais saudáveis quando necessário. Graças aos avanços nos sistemas de georreferenciamento e de novos softwares, é possível criar um banco de informações de árvores atualizado e dinâmico.

Para a gestão da arborização urbana é imprescindível escolher desde o projeto quais espécies a serem utilizadas, considerando fatores como: largura das calçadas, interferência com as infraestruturas, tipo de via, entre outros. Os manuais e as normativas de espécies a serem plantadas geralmente consideram a cidade de forma genérica, sem considerar particularidades locais. Uma sibipiruna pode ser inadequada em rua estreita, e uma aroeira-salsa pode não proporcionar um percurso sombreado em uma calçada larga.

Há oportunidades em parcerias entre agentes privados e o terceiro setor na gestão da arborização urbana. Em São Paulo, a SVMA e a Subprefeitura Vila Mariana fecharam Termo de Cooperação com uma construtora em 2013 no plantio e monitoramento de 160 árvores nas calçadas e canteiro central da Rua Vergueiro, entre as estações Paraíso e Vila Mariana. A parceria contou com o suporte técnico dos órgãos públicos e o plantio e monitoramento pela construtora. A cooperação durou três anos, e mostra como a soma do conhecimento técnico de órgãos públicos com a agilidade do setor privado pode impulsionar a arborização urbana e abre oportunidade com universidades, escolas e postos de saúde locais, associações de bairros, organizações não-governamentais (ONGs) e coletivos.

Outro exemplo de parceria com agentes privados é o Projeto Pomar Urbano, que visa recuperar a vegetação ciliar do Rio Pinheiros entre Socorro e Vila Leopoldina. Desde 1999, o governo estadual, por meio da SIMA, conseguiu viabilizar e consolidar a arborização implantada ao longo do rio e tem realizado parceria com empresas para projetos, plantio e manutenção da vegetação, em troca de realizar publicidade no local. Em mais de 20 anos de projeto, foram plantadas mais de 40 mil árvores em uma área de 273 mil m². A importância do Pomar Urbano é maior pelos serviços ecossistêmicos prestados do que pela percepção da paisagem e integração com o cotidiano, visto que a Marginal Pinheiros é uma barreira que separa a área verde dos bairros adjacentes. No entanto, ao circular de carro é possível 
perceber a diferença que foi implementada e mais recentemente com a implantação da ciclovia, essa qualidade pode ser aproveitada mais de perto pelos usuários.

\section{Redesenho Viário - Ampliação das Possibilidades de Plantio}

A arborização urbana como atividade pontual, pode ser pensada como componente que traz a diversidade para o espaço urbano, é possível organizar manchas de composição de habitats a serem implantados ou grandes conexões entre habitats existentes, capazes de introduzir ou incrementar os espaços do dia a dia e ao longo do tempo, de forma muito próxima da população.

Para isso, a avaliação do sistema viário existente e a hierarquização do uso para a locomoção automotiva é fundamental, de modo a se utilizar a infraestrutura existente, sem prejudicar os fluxos, como demonstram as iniciativas de "Ruas Completas", incentivado pela WRI Brasil (World Resources Institute) e os redesenhos de ruas propostos pela National Association of City Transportation Officials (NACTO), que valorizam a apropriação dos espaços pelas pessoas e outras possibilidades de locomoção. Com a inclusão dos jardins de chuva, é possível a ampliação das áreas permeáveis que fornecem suporte para a vegetação e por conseguinte, maior possibilidade de absorção de água, inclusão de arbustos e forrações, possibilidade de enriquecimento do solo, mais permeável e com desenvolvimento de microrganismos e melhoria na qualidade da água que chega ao sistema de drenagem convencional.

A fim de ilustrar a ideia de ruas bioconectoras, em uma infraestrutura urbana já existente, propomos em uma primeira aproximação, ruas com características que descrevemos aqui como segue (Fig. 6):

- Ruas compartilhadas, sem conexões, com característica de acesso local dos moradores, compartilhamento do espaço por carros, ciclistas e pedestres e nivelamento sem diferenciação entre calçada e leito carroçável e limite de velocidade controlado; com prioridade para o pedestre;

- Ruas locais caracterizadas por conexões apenas de trânsito local do bairro, com redução do leito carroçável, ampliação das calçadas, sinuosidade no traçado e redução do raio de concordância das esquinas para redução da velocidade;
Conexões na paisagem - $A$ arborização urbana como infra-estrutura bioconectora

- Ruas de ligação não têm alteração no traçado, mas ampliam as áreas ajardinadas, utilizando como referência o acesso aos lotes e, finalmente;

- Vias com canteiro central, com calçadas similares às vias de ligação.

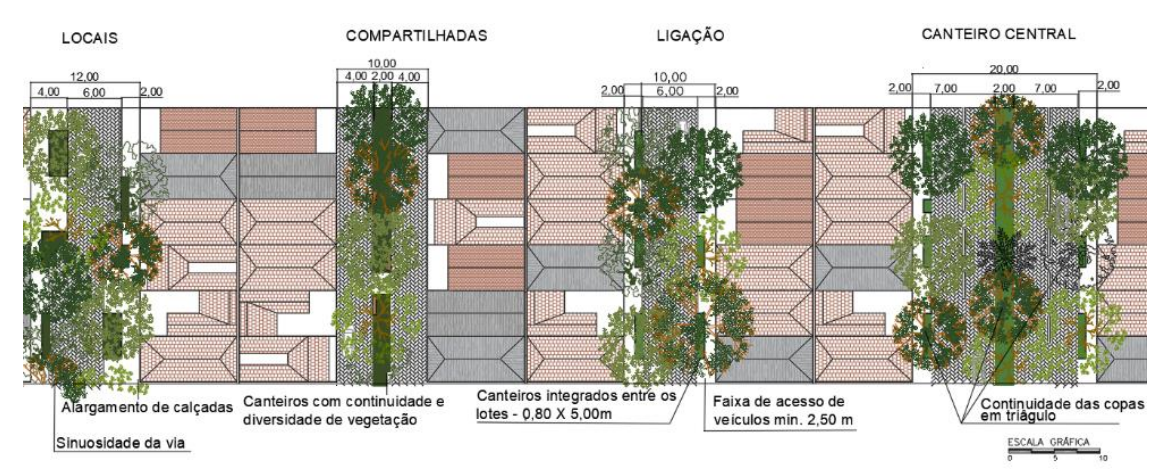

Figura 6 - Plantas das ruas propostas. Fonte: Acervo do GEP Camboatã - elaborado por Annie B. C. da Silveira

A fim de criar espaços mais generosos para o plantio da vegetação, para ruas compartilhadas e ruas locais, partimos do pior caso, com ruas com 10,0 m de largura e testadas dos lotes de $5,0 \mathrm{~m}$. Dessa forma, situações existentes mais favoráveis tanto na largura da rua quanto na testada do lote, podem trazer maior amplitude na proposta.

Para as ruas de ligação, propomos rebaixamento de guia de 2,5 $\mathrm{m}$ para acesso de veículos em cada lote, de modo que os jardins de chuva possam se agrupar e ter $1,0 \mathrm{~m} \times 5,0 \mathrm{~m}$, o que fornece maior área de infiltração e maior possibilidade de solo para o plantio das árvores, mantendo-se largura de leito carroçável de no mínimo 6,0 m. Utilizamos de forma geral a distância mínima de 10,0 m entre o plantio de arbóreas, de modo que as copas possam se tocar e fornecerem a continuidade aérea no ambiente.

As ilustrações a seguir (Fig. 7) mostram as propostas para cada tipo de rua, sem fechamentos dos lotes que segregam o espaço público do espaço privado e, a longo prazo, a expectativa de que a partir de educação ambiental, apropriação dos espaços e conscientização, a possibilidade de integração de pequenos jardins do espaço 
privado integrados ao espaço da calçada ou área pública, inclusive com maior área permeável nos lotes e plantio de vegetação nessa área privada integrada às áreas públicas.

Para as ruas locais, com o uso de redesenho da via, é possível manter as dimensões descritas, com a inclusão da sinuosidade no leito carroçável, para redução da velocidade dos veículos e quando possível, com o alargamento das calçadas (para ruas com mais de $10,0 \mathrm{~m}$ de largura).

As ruas compartilhadas pressupõem apenas o acesso aos imóveis, sem distinção entre leito carroçável e calçada, já que a prioridade é do pedestre, com faixas de no mínimo 4,0 m de largura para acesso aos lotes, área central com jardins de chuva com no mínimo 2,0 m de largura por toda a extensão da rua, interceptadas por passagens intervaladas. Para ruas com comprimento superior a $40 \mathrm{~m}$ é necessária a previsão de hidrantes ou largura mínima de 6,0m para a segurança a incêndio. Dessa forma, pressupõe-se que a arborização poderá contar com maior área de solo permeável, além de se integrarem aos estratos arbustivos e de forração, trazendo maior diversidade e possibilidades de associação com a fauna.

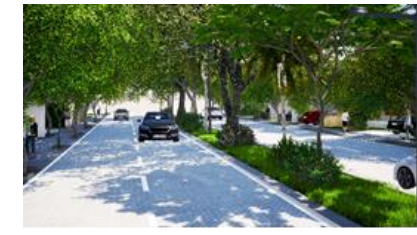

Rua com canteiro central

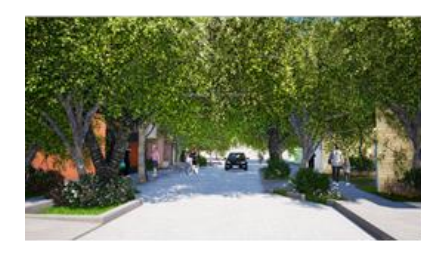

Rua local

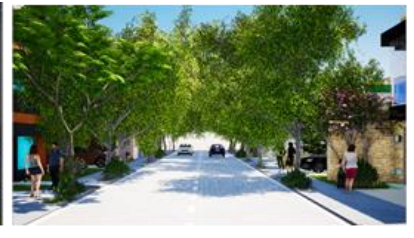

Rua de ligaçäo

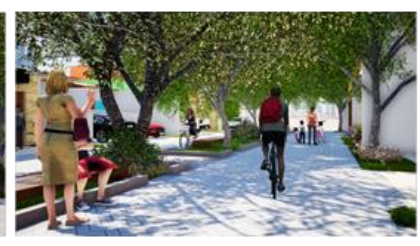

Rua compartilhada
Figura 7 - llustração das ruas propostas, com continuidade das manchas de copas das árvores e maior integração de áreas ajardinadas. Fonte: Acervo do GEP Camboatã - elaborado por Annie B. C. da Silveira

Texto original: Las áreas urbanas son los principales contribuidores al cambio climático; si bien cubren sólo el dos por ciento de la superficie de la tierra, producen más del 70 por ciento de las
Conexões na paisagem - A arborização urbana como infra-estrutura bioconectora

Com a alteração dos espaços públicos da rua é possível intensificar o plantio da vegetação, a proximidade entre as copas, a disposição dos vários estratos arbóreos, arbustivos e de forração, além de aproximar os moradores de uma gama muito maior de atividades bióticas na vida urbana, de modo a incentivar também que essas áreas públicas se conectem a jardins da parte privada do lote, ampliando a área permeável e de vegetação/conexões.

\section{Questões bioclimáticas}

A questão bioclimática versus perda de áreas verdes tem sido destacada por diversos autores nos estudos sobre São Paulo, no sentido de que existem dados esclarecedores que apontam para a urgência de ações que possam conter $o$ aumento médio da temperatura no meio urbano. Pode ser observada em mais de uma escala, seja no âmbito da metrópole paulistana, ou nas questões de saúde pública dos bairros periféricos no município. Existe relação direta entre as ilhas de calor e os problemas relacionados ao aumento da média histórica da temperatura, principalmente em áreas que tradicionalmente apresentam completa infraestrutura urbana $e$ índice mínimo de cobertura vegetal.

\section{Clima}

Entidades promotoras de políticas globais são fundamentais para a construção de conceitos como a Food and Agriculture Organization of the United Nation (FAO) para reversões futuras do quadro das mudanças climáticas a partir da experiência em cidades de diversos países, principalmente, aqueles em desenvolvimento:

As áreas urbanas são o principal contribuidor às mudanças climáticas; apesar de cobrirem apenas somente dois por cento da superfície da Terra, produzem mais de 70 por cento das emissões de gás carbônico do mundo, além de enormes quantidades de outros GEE (gases de efeito estufa). As áreas urbanas são também altamente vulneráveis ante as mudanças climáticas (FAO, 2017 p. 62 - tradução nossa) ${ }^{1}$.

emisiones de gas carbónico del mundo, además de enormes cantidades de otros GEl. Las áreas urbanas son también altamente vulnerables ante el cambio climático. 
Segundo Romero (1988) apud Rossetti et al (2009), a definição de fatores climáticos locais afirma serem aqueles condicionados pela topografia, vegetação, superfície do solo natural e construído. A vegetação, especificamente, estabiliza os efeitos do clima sobre seus arredores imediatos, reduzindo as variações extremas ambientais.

Ele classifica como elementos climáticos aqueles representantes dos valores de cada tipo de clima, a saber: temperatura, umidade do ar, precipitações e movimentos atmosféricos.

A Unidade Climática Urbana Central apresenta o primeiro processo de urbanização a partir do núcleo fundador da Cidade de São Paulo, e suas interações junto a outras unidades descritas pelos autores:

O primeiro nível estabelecido é o da passagem dos climas urbanos locais para as Unidades Mesoclimáticas Urbanas. A extensão do fenômeno metropolitano ultrapassa o nível local, abrangendo o sub-regional, envolvendo, modificando e transportando energia, poluentes e sua atmosfera urbana para outros climas locais da bacia do Alto Tietê (TARIFA \& ARMANI, 2001, p. 48).

Portanto, um fator importante levantado pelos estudos apresentados, é o do transporte para áreas vizinhas, ou seja, as influências que se expandem no meio atmosférico pelas alterações de qualidade do ar, aumento de temperatura, e ação de outros poluentes e materiais particulados.

Apesar da pouca diferença de temperatura média entre os dois núcleos escolhidos, dados como "Material particulado e poluição fotoquímica (NO e O3)" apresentam uma relação entre baixa taxa de áreas verdes e concentração destes poluentes.

As avaliações também sugerem o benefício combinado da maior área vegetada em Pinheiros, e menor índice de verticalização, em contraste com a baixa dispersão na região Central.

É importante lembrar que este estudo é sempre apresentado em conjunto com o Mapa das unidades climáticas naturais. Entretanto, no caso presente, o foco recai sobre a arborização urbana e suas possibilidades relacionadas ao Clima Urbano.
Grupo de Estudos e Práticas Camboatã Território - Natureza, et al. Conexões na paisagem - $A$ arborização urbana como infra-estrutura bioconectora

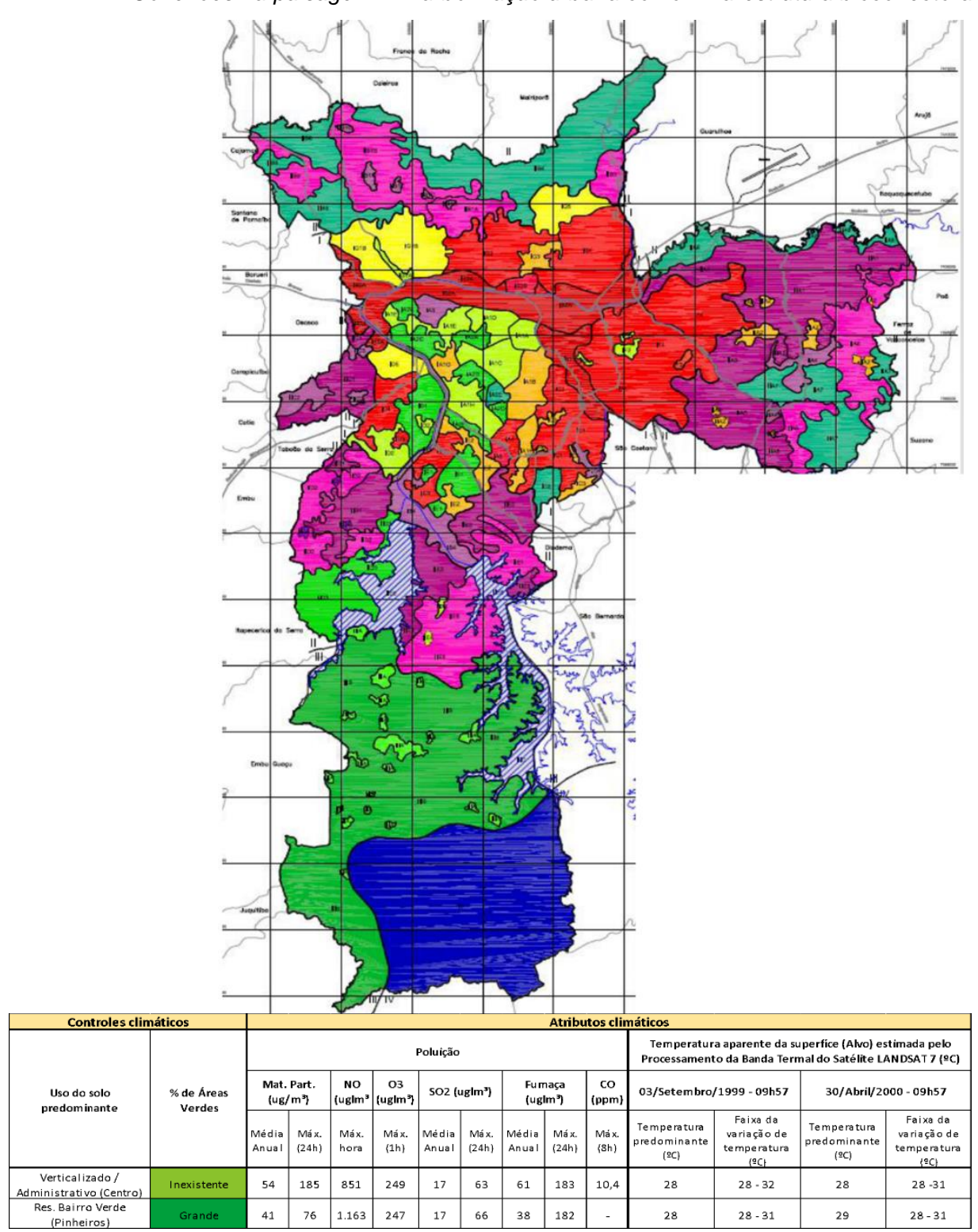

Figura 8 - As manchas de cores apresentam os blocos formadores de unidades climáticas urbanas. O resultado desses agregados está intimamente ligado ao status de cobertura por áreas verdes - em uma escala que vai desde inexistente (verde claro) à grande cobertura (Verde escuro). dos tota incluem poluição atmosférica. Fonte: Atlas Ambiental de São Paulo, 2000. 


\section{Temperatura}

Sendo uma das questões colocadas - o status das políticas públicas aplicadas à revegetação urbana - seria importante rever alguns conceitos em uso. Tal abordagem procura mostrar metodologias para análise (reversão das mudanças climáticas) na esfera abiótica em grandes aglomerados urbanos, e o comprometimento de Prefeituras como a paulistana, e seus respectivos planos para reduzir os efeitos sobre os microclimas locais.

Na figura 9 destaca-se com clareza a média climatológica, curva 1991 - 2015, e, sucessivamente as de 2014 e 2015, desenhando um contorno de alta da média de temperatura no período. Calcada nos dados de perda de vegetação contidos no Atlas Ambiental de 2002 e outras fontes de dados, a relação fica bastante clara.

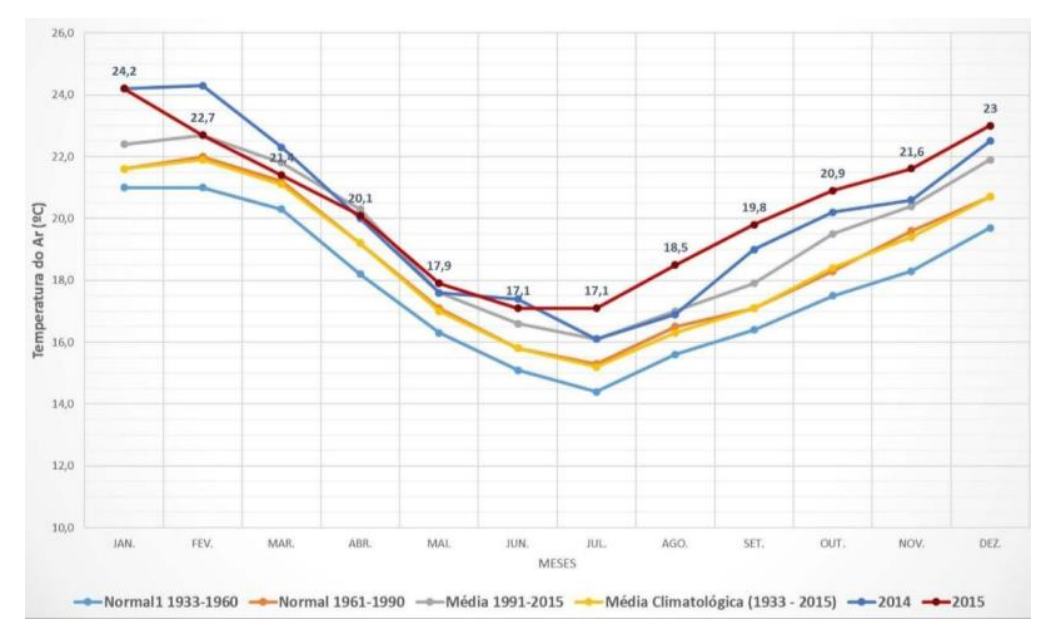

Figura 9 - Comparação da temperatura média do ar anual no município de São Paulo. Fonte: Instituto Astronômico e Geofísico da Universidade de São Paulo.

\section{Ilhas de calor e uso da arborização}

Spangenberg (2019), atualiza o conceito de ilhas de calor, comparando-as ao conceito (oposto) oásis de verão. Alguns materiais de construção convencionais que absorvem calor, tornam algumas áreas da cidade mais superaquecidas do que outras. Outras características dentro da cidade, podem apresentar processos de agravamento, segundo o autor: "Sobretudo nos bairros de construções baixas com fatores de visibilidade do céu (sky view factors - SVF), com pouca sombra vegetal, tendem a desenvolver ilhas de calor nos dias ensolarados, retendo e emitindo a energia absorvida até altas horas da noite, levando a clima urbano quente e seco (desértico)" (SPANGENBERG, 2019, p. 73). O autor descreve o clima oásis de verão como algo mais confortável, típico de áreas próximas a corpos d'água e expressivos fragmentos de áreas verdes (parques, vias densamente arborizadas), resultando em superfícies sombreadas e por consequência, relativamente frias.

Comparando temperaturas entre arredores rurais da metrópole e centro adensado, Spangenberg afirma que as diferenças entre ilhas de calor e oásis de verão, podem apresentar diferenças entre $10^{\circ}$ e $12^{\circ} \mathrm{C}$. Já na escala entre bairros urbanos, citando tal diferença seria entre $1^{\circ}$ e $5^{\circ} \mathrm{C}$, principalmente entre parques e vias com árvores esparsas.

$\mathrm{Na}$ área central e em algumas áreas periféricas, pode-se enumerar: solo e lençol freático contaminados, construções sub habitadas, geração de calor intenso aumentando a média de temperatura do entorno por reflectância e absorção dos materiais, aridez e secura do ar, e pouca ou quase nenhuma área verde.

\section{O uso das espécies nativas - $O$ aproveitamento dos serviços ecossistêmi- cos dentro da arborização urbana}

Os espaços públicos verdes são os componentes urbanos mais próximos que temos do habitat natural em que o ser humano se originou e do qual sempre dependerá. O habitat humano urbano construído por séculos trouxe problemas que poderiam ser amenizados e/ou sanados por meio de uma abordagem projetual e de ação envolvendo uma análise dos serviços ecossistêmicos prestados.

Complementar aos serviços ambientais, que são os serviços da sociedade para com o meio ambiente, e denominados pela Empresa Brasileira de Pesquisa Agropecuária (EMBRAPA) como "benefícios ambientais resultantes de intervenções intencionais da sociedade na dinâmica dos ecossistemas, tais como as atividades humanas para a manutenção ou a recuperação dos componentes dos ecossistemas" (EMBRAPA, 2015), os serviços ecossistêmicos de que se trata aqui também incluem os benefícios para os seres humanos do manejo de ecossistemas naturais, ou seja, conforme caracterizados por Constanza et al. (1997), são aquelas "funções 
ou processos que contribuem direta ou indiretamente para o bem-estar humano", benefícios que as pessoas podem obter a partir do funcionamento dos ecossistemas saudáveis.

Na Avaliação Ecossistêmica do Milênio (Millennium Ecosystem Assessment MEA), organizada por Kofi Annan, Secretário-Geral da Organização das Nações Unidas, os serviços ecossistêmicos podem ser classificados em quatro categorias: provisão, regulação, suporte e cultural. O serviço de suporte é o único que está diretamente ligado aos outros três por oferecer, como a própria designação, suporte para que os outros aconteçam, envolvendo a manutenção do meio de fornecimento, a exemplos de qualidade do solo, garantia de biodiversidade, polinização. O serviço de provisão envolve o fornecimento de matérias primas básicas e suprimentos como comida e água. O serviço de regulação trata da qualidade climática (temperatura, ar, chuva) e o serviço cultural oferece lazer, saúde mental e física, além de cultura (MEA, 2003).

Segundo Bolund e Hunhammar (1999), ao menos 6 serviços ecossistêmicos são prestados em espaços verdes, eles são: filtragem do ar, regulação do microclima, regulação de ruído, drenagem de águas pluviais, tratamento de esgoto, recreação e cultura estes definidos, conforme Figura 10:

\begin{tabular}{|c|c|}
\hline BENEFícIO AO BEM ESTAR HUMANO & SERVIÇO ECOSSIITÉMICO PRESTADO \\
\hline FILTRAGEM DE AR & As plantas têm uma alta capacidade de remoção de particulados \\
\hline REGULAÇÃO DO MICROCUMA & $\begin{array}{l}\text { Através da evapotranspiração promovendo resfriamento e a } \\
\text { sombra projetada das copas que diminui a temperatura ambiente }\end{array}$ \\
\hline REDUÇão DE RUÍDO & $\begin{array}{l}\text { Capacidade de absorção do som e retardamento da velocidade do } \\
\text { vento }\end{array}$ \\
\hline $\begin{array}{l}\text { DRENAGEM DE ÁGUAS } \\
\text { PLUVIAIS }\end{array}$ & $\begin{array}{l}\text { Potencial de absorção diminuiç̧ăo da proporçăa e quantidade de } \\
\text { alagamentos, inundaçôes e erosôes }\end{array}$ \\
\hline TRATAMENTO DE ESGOTO & Capacidade de retenção de nitrogênio e fósforo \\
\hline RECREAÇÃO E CULTURA & Reduç̃oo de estresse, bem estar físico-emocional \\
\hline
\end{tabular}

Figura 10 - Relação serviços ecossistêmicos e benefícios ao bem estar humano. Fonte: BOLUND e HUNHAMMAR (1999), tradução nossa.
Conexões na paisagem - $A$ arborização urbana como infra-estrutura bioconectora

De maneira geral, ecologia da paisagem também significa relações entre as populações nela estabelecidas. Num ambiente urbano, de maneira inspirada na natureza, trata-se de conduzir as populações a um estado de equilíbrio tal que o sistema ofereça suporte a todos os nichos de espécies em seus habitats. Na cidade, portanto, o desafio consiste em elaborar suporte semelhante (recursos), num cenário de redução de território, mudanças importantes na média de temperatura, redução no grau de umidade do ar (Flora), e abrigo para Fauna, entre outros fatores. Se nos parques com seus núcleos de floresta nativa, esses processos já existem, trata-se de trazermos tais relações bióticas à arborização urbana (essencialmente linear).

Portanto, fica claro também, que nos processos de arborização em vias desprovidas de vegetação, com tendência a microclimas áridos, os habitantes - ativistas e os programas de recuperação ambiental desenvolvidos são que fazem papel de provedores de suporte, ou recursos à flora e fauna locais, numa primeira fase, para as faixas arborizadas (manejo durante a infância e juventude das espécies plantadas).

Ações já citadas como: projetos de manejo, uso correto das espécies arbóreas buscando seu máximo potencial dentro dos serviços ecossistêmicos: individual - (atributos estéticos como floração, frutos, estrutura), abrigo para fauna - e coletivamente - melhorias microclimáticas, identificação com a geografia regional, adequação ao ambiente entre outras qualidades já citadas anteriormente - é que conduzirão ruas arborizadas ao patamar de vias bioconectoras.

Sabemos há algumas décadas que é possível ir além da floresta urbana pensada como extensão dos jardins de espaços públicos provedores de sombreamento e lazer, contendo, majoritariamente, espécies exóticas, e voltados basicamente à apreciação estética, (não menos importantes ecologicamente).

Aprendemos que a visão sistêmica garante a gestão eficiente das informações necessárias ao planejador, e vimos que programas municipais de arborização urbana e processos de gestão compartilhada com a sociedade, estão sob guarda-chuvas de protocolos e diretrizes internacionais, ligados às agências e ONGs fomentadoras de programas ambientais.

No tópico Planejamento, Projeto e Gestão, voltado exclusivamente à implantação, fomento e recuperação de Florestas Urbanas, organizações como a Food and Agri- 
culture Organization of the United Nations (FAO), transformaram todo um acervo de experiências, em princípios e diretrizes para as cidades conectadas.

\section{Diretrizes da FAO para gestão de Florestas Urbanas}

Entre diversas funções das florestas urbanas vale destacar o ciclo de gestão das manchas florestais e fixação de carbono segundo a FAO (2017), mantendo e enriquecendo a biodiversidade das formações florestais nas cidades (Fig. 11).

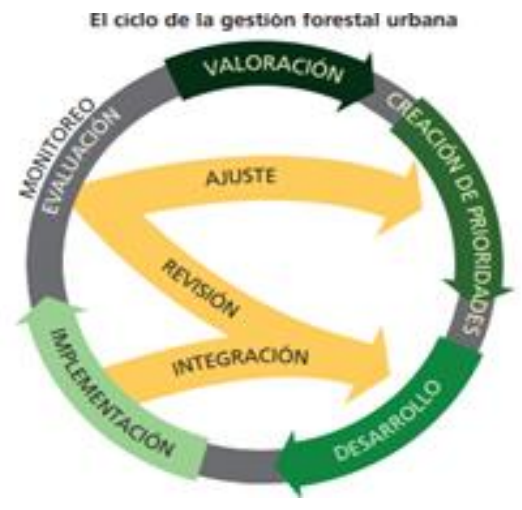

Figura 11 - Ciclo de gestão das florestas urbanas. Fonte: FAO, 2017.

Neste sentido, a FAO (2017) estabelece três diretrizes para as florestas urbanas: promoção de espécies autóctones para criar coberturas de copas que possam aumentar a absorção de carbono; avalição das áreas verdes existentes, do ponto de vista do serviço ecossistêmico, dos benefícios, do capital natural e humano; e inventário completo, parcial ou amostral das árvores em áreas verdes existentes.

As reflexões desenvolvidas convergem para o termo mais importante para a arborização de vias, sob a ótica da ecologia da paisagem: conectividade. Como exemplo de conectividade, uma rua bioconectora (Fig. 12) pode ter árvores com intervalos entre 4 e 6 metros para acesso de veículos aos lotes. Esta distância entre elas possibilita a avifauna utilizar como corredor de alimentação ou trajeto.

Esta possibilidade de redesenho de ruas permite espaços mais contínuos de inclusão de áreas ajardinadas, de modo a intensificar a existência de áreas permeáveis,
Grupo de Estudos e Práticas Camboatã Território - Natureza, et al.

Conexões na paisagem - $A$ arborização urbana como infra-estrutura bioconectora mais espaço para as raízes e a intensificação das relações entre os estratos arbóreos, arbustivos e de forração com os microrganismos presentes no solo.

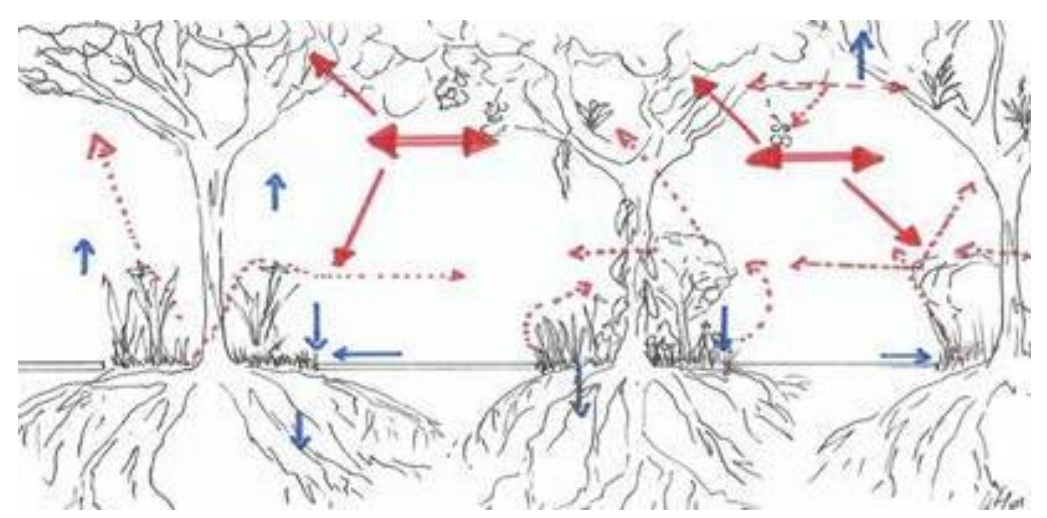

Figura 12 - Representação de plantio de árvores em ruas. Setas vermelhas grossas indicam o trajeto, altura usual e corredor de alimentação das espécies de avifauna. As setas vermelhas mais finas indicam os trajetos de predação de pássaros insetívoros a partir das árvores. As setas verarbórea. As setas azuis representam o ciclo da água. Elaboração: Sidney Carneiro Mendonça Fernandes.

A perspectiva é a de conexão de áreas vegetadas existentes e intensificação da arborização em ruas ressignificadas como bioconectoras, levando em consideração questões centrais em relação à Ecologia da Paisagem ali presente: biomas locais (Domínio da Floresta Atlântica), solo e seus ciclos bioquímicos, vegetação (árvores, arbustos, herbáceas) com microfauna associada e matéria orgânica resultante, ciclo da água (no subsolo, em associação à vegetação, na umidade do ar, como fator de saúde pública), sempre face à morfologia urbana existente e Programas Socioambientais a serem estimulados.

O Poder Público juntamente com outras entidades envolvidas com o tema tem condições de fazer as avaliações projeções na escala macro, de forma a indicar ações, prioridades e metas a serem buscadas, como caracterização física e biótica, diversidade a ser obtida em cada região ou compartimento da cidade, conexões desejadas entre maciços existentes, espécies de fauna e flora a serem estimuladas. Com isso, é possível por meio de programas de incentivo, incorporar ações locais que 
venham a colaborar para a obtenção dos resultados e, a longo prazo, transformar o entendimento de cidade e de envolvimento de cada um com o todo.

A possibilidade de cultivar coletivamente uma floresta urbana que aponte para a recuperação da paisagem, com a possibilidade de .ensaiar o planejamento da utilização das calçadas das ruas de forma sistêmica - em um cenário de ação imediata, com a otimização da arborização urbana como parte de uma espécie de parque difuso em que se transformam os bairros a partir desse tipo de ação e, em um momento posterior, a perspectiva de uma ampliação das áreas vegetadas no âmbito das ruas, conquistando faixa de estacionamentos em nome da visão renovada da vegetação urbana como infraestrutura verde, com serviços ecossistêmicos valorizados e apontando para uma condição regenerativa.

\section{Educação nas várias escalas}

A educação é fator fundamental no redesenho das ruas e na qualificação dos seus espaços, em especial ao considerarmos que a manutenção e controle desses espaços depende basicamente da apropriação pelos agentes que os compõem.

Essa educação passa pelas várias escalas de intervenção e compreensão da importância que a melhoria da qualidade urbana depende de cada um. Existe atualmente a ideia compartilhada sobre a necessidade de manutenção e preservação de áreas verdes e remanescentes de vegetação, mas de certa forma essa compreensão está muito baseada na regulação das atividades do "outro", como se tivéssemos que nos apegar apenas a lutar por aquilo que não foi completamente degradado, sem avaliarmos que a mudança de atitude para com o espaço urbano pode construir novas formas de relações bióticas, que podem ser bastante interessantes. As gerações atuais em geral têm pouco contato com a terra, a diversidade e a identificação de espécies, seja da flora ou da fauna, em uma compreensão distante da realidade, mas muito conscientes do tema preservação de tudo o que está longe do seu dia a dia. Quantos criticam o desmatamento sem nunca terem plantado ou cuidado de uma única árvore, ou pior, não perceberem aquelas que estão no seu caminho diário? O que dizer então da infinidade de possibilidades que estão latentes para serem incorporadas na rotina urbana?

A educação com relação à biodiversidade não deveria se restringir aos habitats mais preservados, mas incorporar o cotidiano e a possibilidade da qualidade ambiental seja no espaço da escola, da rua ou da residência. Criar condições para interações bióticas na realidade do dia a dia, pode trazer possibilidades e uma geração mais conectada com o seu potencial individual de intervenção e de reeducação familiar, assim como já acontece em um certo grau sobre o consumo da água e a reciclagem do lixo.

Nos cursos de paisagismo na faculdade de arquitetura, por exemplo, é comum o encantamento dos alunos com a descoberta no seu percurso de potenciais elementos que eles não tinham sido educados para enxergar, como as texturas, as cores e a dinâmica da presença da vegetação no ambiente urbano. Fica claro também como essa incapacidade para enxergar retira a possibilidade de qualificação dos seus espaços de vivência, com a constatação das diferenças com relação à presença da vegetação nas diferentes áreas da cidade, sem encontrarem incentivos para a transformação, ainda que haja vários estudos relativos à qualidade do clima e da temperatura nas áreas mais arborizadas. É fundamental que as várias disciplinas, quer da arquitetura ou da engenharia incorporem a presença da vegetação como elemento da infraestrutura urbana de forma mais consistente nos projetos, aliadas às outras áreas do conhecimento, assim como a biologia, botânica, geologia sejam mais participativas nas concepções projetuais. A interdisciplinaridade precisa acontecer também no cotidiano.

Para os profissionais da engenharia ou arquitetura que intervêm diretamente no espaço urbano, em geral, o conhecimento da vegetação é absolutamente secundário e não aparece de forma consistente nos projetos, para não comprometer visuais, não danificar edifícios ou mesmo pelo próprio desconhecimento de características específicas, dimensões e necessidades, o que em geral faz com que o tema seja relegado a projetos complementares que não caminham junto com a concepção inicial e muitas vezes se limitarem a uma ação de finalização de obra.

É nesse sentido que os órgãos que compõem o Poder Público, além de suas competências de regulação e controle, têm papel fundamental como promotores de qualidade e poderiam se comprometer mais como agentes propositores. O Poder Público possui em seus quadros técnicos capacitados e ainda dispõe de mecanismos para a contratação de projetos interdisciplinares, é capaz de propor cenários viáveis de longo prazo, de forma que haja um plano setorizado de espécies e diversidade desejável para cada região da cidade, adequadas ao entrelaçamento ecossistêmico 
entre vida urbana, fauna e flora. Esse cenário ou cenários desejáveis podem servir de orientação para ações locais, seja do próprio Poder Público, como também de agentes de empresas privadas, de associações ou coletivos e até mesmo dos moradores locais.

A arborização urbana na sua implantação e manutenção traz consigo também a questão do limiar entre o público e privado, assim como acontece com as calçadas, que existem em todos os lugares: ricos, pobres, sofisticados, vulgares, junto a monumentos, a grandes edifícios ou à casa autoconstruída, guardando sempre a escala humana na cidade. Ambas têm o Poder Público como o regulador dessa qualidade, mas pelo seu caráter ligado ao proprietário do lote, permitem também movimentos de grupos ou particulares, já que cada indivíduo pode colaborar de forma simples e de baixo custo, com o plantio na frente do seu lote, por exemplo. Movimentos educativos têm a possibilidade de engajar a população para atuar na meIhoria da qualidade urbana. Pensemos nas grandes manchas urbanas carentes de arborização e que poderiam ter movimentos de plantio em suas ruas desérticas. A arborização urbana pode ser conectada a um programa de implantação e de conscientização, que utiliza o morador como agente de programas do tipo "adote uma árvore", que já teve experiência realizada na década de 1970 na cidade de São Paulo e que tem iniciativas atualmente em várias cidades. A ideia de trazer para próximo das pessoas a responsabilidade por um ambiente urbano qualificado, junto com educação, aproxima a população das questões ambientais e pode trazer de volta a relação que já existiu com os quintais. Iniciativas desse tipo podem qualificar regiões da cidade extremamente áridas, com os agentes locais.

No entanto, é fundamental a educação nos vários níveis, de forma que a legislação seja mais do que regras a serem cumpridas, mas antes, seja conteúdo nas escolas de todos os níveis, o que trará a conscientização para os vários agentes públicos e privados.

\section{Considerações finais}

A arborização de ruas e calçadas como o espaço público do cotidiano da cidade coloca luz sobre as possibilidades que esses espaços podem protagonizar na relação intrínseca da fruição e uso da cidade com os elementos da natureza, na conexão com outros espaços arborizados ou com remanescentes de vegetação, com todas as espécies de vida que estão ao nosso redor e no papel que temos como agentes que impactam e são impactados de uma forma mais virtuosa, seja no planejamento e projeto ou na concretude da vida local. Imaginar a multiplicidade do conhecimento amalgamado na soleira das portas, que traz saúde, ar mais puro e respirável, em meio à dinâmica da vida que explode em cores, cheiros e texturas, traz mais a ideia da cidade como um grande jardim ou quem sabe a roça e quintais do passado, ligados ao cotidiano das pessoas.

Trazer para a arborização urbana o conhecimento acumulado sobre os serviços ecossistêmicos é incluir no espaço do cotidiano a possibilidade de uma vida mais conectada alinhada com a qualificação ambiental do espaço urbano e engajamento da população local com o papel que cada um pode desempenhar para uma cidade mais amistosa e agradável.

A possibilidade de uso da quantidade incrível de espécies que estão presentes nestes nossos ares, pode trazer para a arborização urbana uma outra perspectiva de infraestrutura, conectada por meio de ramificações de um sistema que carrega a vida e a diversidade tão almejada, permeando toda a cidade, ora com ligações mais estruturais e compactas, ora com possibilidades menos pretensiosas e tênues, mas que têm seu papel no grande mosaico.

Incluir a arborização urbana como elemento da educação e conscientização pode formar novas gerações mais conectadas com o seu papel como agentes atuantes na melhoria e recriação do ambiente urbano, conscientes de que não basta preservar áreas de vegetação existente ou remanescentes, mas de perceber nosso papel como construtores do ambiente que desejamos viver e deixar como herança.

Poder contar com um Poder Público mais propositivo na escala do planejamento, que define grandes manchas de diversidade e conexões, pode orientar na escala local a implementação de políticas de arborização e revegetação que aconteçam tanto em intervenções de obras públicas, como de comunidades e até do indivíduo. Essa proximidade de intervenção na cidade que se arvora pode trazer maior compreensão do papel que cada um exerce na construção do nosso espaço, seja no limiar do público ou que adentra para a privacidade do lote.

A cidade é a consolidação de diversas disciplinas, e a arborização urbana é um exemplo disso. É uma das muitas interfaces entre arquitetura, engenharia e biologia, onde a soma delas podem resgatar a natureza como integrante da cidade e não 
como um assunto antagônico. Para isso é preciso entender a arborização como estrutura global, em que pequenas partes das ações locais articuladas formam a sua totalidade.

O Poder público na forma de gestões municipais, possui a condição ideal em termos de qualidade e quantidade de informações, para ser o Planejador / Propositor de políticas que permeiam a articulação dos espaços arborizados ou por arborizar, de modo a propor a ecologia aplicada ao meio urbano como um grande tema, apto a abrigar a diversidade dos movimentos ativistas e manter estreitos contatos junto às comunidades organizadas locais, chegando ao dia a dia do cidadão, por metodologias em consonância às múltiplas realidades do universo paulistano, de maneira clara e objetiva.

O momento envolve simplificar o idioma científico a todos, indiscriminadamente, a fim de se criar um código de leitura fácil e eficiente que torne o meio urbano do regional ao local habitável às árvores do Bioma Mata Atlântica, reparando uma lacuna histórica no repertório cultural da população do município. Seu sistema sucessional serve como elemento inspirador de objetivos claros, eficientes e de natureza educadora aos participantes de programas de arborização. Poderá chegar, com o tempo, o universo da Cultura transformadora - esta sim, aglutinadora das melhores expectativas.

Entre as várias questões urgentes atreladas às práticas educadoras da silvicultura urbana, espera-se o rompimento de barreiras limitadoras da percepção do uso dos espaços habitados (hoje assépticos, "privativos", compartimentados e vigiados no pior sentido do termo). Neste sentido, algo como um sistema que desvanece as diferenças entre Cidade e Natureza por meio de um continuum de vida, ou seja, um princípio norteador para os espaços adoecidos da cidade.

Evidenciar a natureza que ocorre no nosso cotidiano traz para diversas pessoas a percepção que ela não está a centenas ou milhares de quilômetros de distância, mas ao nosso redor, com melhores benefícios ao microclima, à qualidade do ar e o incremento da fauna e flora dentro de nossas cidades. Mostrar a natureza na cidade é promover a conscientização ambiental e a percepção que cada um faz parte deste todo.

\section{Referências}

BOLUND, P. HUNHAMMAR, S. Ecosystem Services in Urban Areas. Ecological Economics, no 29, 293-301. 1999. Disponível em: http://www.fao.org/uploads/media/Ecosystem_services_in_urban_areas.pdf. Acesso em 25/07/2021.

COSTANZA, R., D'ARGE, R., DE GROOT, R., FARBER, S., GRASSON, M., HANNON, B., LIMBURG, K., NAEEM, S., O'NEILL, R., PARUELO, J., RASKIN, R., SUTTON, P., VAN DEN BELT, M., 1997. The value of the world's ecosystem services and natural capital. Revista Nature 387 (15), 253-260

\section{EMBRAPA, Serviços Ambientais em Sistemas Agrícolas e Florestais do Bioma} Mata Atlântica. Distrito Federal, Brasilia, 2015.

FAO (Food and Agriculture Organization of the United Nation), 2016. Directrices para la silvicultura urbana y periurbana, por Salbitano, F., Borelli, S., Conigliaro, M. y. Chen, Y. 2017. Estudio FAO: Montes № 178, Roma, Itália; Disponível em: http://www.fao.org. Acesso em: 15/07/2021

MEA. Millennium Ecosystem Assessment. Ecosystem and Human Well-Being: a framework for assessment. Washington: Island Press, 2003.

NACTO. National Association of City Transportation Officials, Disponível em: https://nacto.org. Acesso em: 15/07/2021.

PAIVA, L. Afastar pedras do caminho e plantar árvores no asfalto. Quando Fernando Haddad adotou solução urbanística de baixo custo. Minha Cidade, São Paulo, ano 18, n. 212.03, Vitruvius, mar. 2018. Disponível em: https://vitruvius.com.br/revistas/read/minhacidade/18.212/6919. Acesso em: 05/07/2021.

ROSSETTI, A. I. N. PELLEGRINO, P. R. M. TAVARES, A. R.; O Espaço na Cidade de São Paulo e sua interface com a arborização: aspectos da transformação socioeconômica do sítio físico e da proteção de vegetais de porte arbóreo. Artigo: Revista da sociedade brasileira de arborização urbana - REVSBAU, Piracicaba - SP, v.4, n.1, p.21-38, 2009. (recebido em 03.09.2008 e aceito para publicação em 19.03.2009). Disponível em: https://www.researchgate.net/publication/332822348. Acesso em: 20/07/2021 
SÃO PAULO (Cidade). Atlas ambiental do município de São Paulo. Fase I: diagnósticos e bases para a definição de políticas públicas para as áreas verdes do Município de São Paulo. Outorgada: Harmi Takiya. Relatório final, julho / 2002, Prefeitura do Município de São Paulo. Disponível em: https://www.prefeitura.sp.gov.br/cidade/secretarias/upload/meio_ambiente/ATLAS\%20AMBIENTALcompactado.pdf. Acesso em: 28/07/2021

SÃO PAULO (Cidade). Lei 13.430, de 13 de setembro de 2002. Plano Diretor Estratégico. Diário Oficial do Município de São Paulo. São Paulo, SP, 14 de setembro de 2002. p. 1.

SÃO PAULO (Cidade). Lei 16.050, de 31 de julho de 2014. Aprova a política de Desenvolvimento Urbano e o Plano Diretor Estratégico do Município de São Paulo e revoga a Lei no 13.430/2002. Diário Oficial do Município de São Paulo. São Paulo. São Paulo, SP, 01 de agosto de 2014. Suplemento.

SÃO PAULO (Estado). Vegetação Significativa do Município de São Paulo. São Paulo: Secretaria do Meio Ambiente/Secretaria Municipal de Planejamento, 1988, 560p.

SPANGENBERG, J. Natureza em Megacidades: Serviços Ambientais da Floresta Urbana. São Paulo - Editora da Universidade de São Paulo, 2019;

TARIFA, J.R \& ARMANI, G. in TARIFA, J.R. \& AZEVEDO, T.R. de (Org..). Os climas na Cidade de São Paulo - teoria e prática. São Paulo GEOUSP - Coleção Novos Caminhos - 4, FFLCH USP;2001

WRI Brasil - World Resources Institute. Disponível em: https://wribrasil.org.br/pt/oque-fazemos/projetos/ruas-completas. Acesso em: 18/07/2021 